\title{
A Case Study on the Contents Creation of Online Lectures to Promote Interest and Concentration of Learners
}

\begin{abstract}
(Open Cyber University of Korea)
Kang, Hye-Kyung. (2018). A case study on the contents creation of online lectures to promote interest and concentration of learners. STEM Journal, 19(4), 127-147.

This study aims to introduce lecture production examples of online English classes, to analyze learners' responses to them, and to present more effective lecture contents and presentation techniques to stimulate learners' interest and concentration. The contents of the lecture consisted of the scenes, dialogues, and sound tracks of movies that learners of different ages with various academic backgrounds and life experiences could have common interest in. In order to effectively present these lessons, the content was strategically produced using PowerPoint and Prezi, based on Gagné's (1985) nine professions. In particular, a lecture that illuminates Van Gogh's life through his paintings attempted to stimulate emotions by using a storytelling format with the Prezi tool and tried to make a lively presentation so students could appreciate the pictures in the gallery. The responses to this technique were surveyed. A total of 167 students participated in the questionnaire. Over $90 \%$ of the students gave positive feedback saying the way of presenting the learning contents using Prezi was helpful. In the descriptive questionnaire, 73 of 91 participants gave positive opinions and 18 suggested improvements. This shows that this model can be used as an example of customized content design that approaches creative ideas strategically.
\end{abstract}

Kang, Hye-Kyung

\section{INTRODUCTION}

Accuracy, fluency, and confidence are three of the most important requirements for a good English speaker. In order to achieve these main objectives, the first thing that is needed is to attract the attention and interest of the learners. To attract learners and make them stay in the classroom is well-designed contents dealing with such interesting materials as timely news, well-known movie scenes and OSTs. Of course, the quality of the content is also important, but first, it is to create well-designed contents to prompt learners' curiosity and to stay in the classroom for a long time. In this paper, therefore, we 
introduce the case of online English lecture which is strategically designed to stimulate learners' interest and concentration, and analyze their responses to it to suggest more effective lecture contents and presentation techniques.

Due to the nature of cyber universities, students from various professions are studying in one classroom. There is a wide range of students from early 20 s to 60 s. Students' academic backgrounds and life experiences vary widely. These diverse students apply for a single goal, a desire to learn English, and to improve their English proficiency. In order to meet these needs, English language course has strategically been developed. It was intended to allow students to experience English naturally through stories and contexts focusing on subjects that can be experienced by anyone in our daily life including work, love, friendship, self-development, and death. In addition, introducing the case of production and analyzing the learners' response to it, the emphasis was on creating content that can integrate the four skills of language learning: listening, speaking, reading and writing.

The purpose of this study is to develop and construct lecture contents that other students who are not majoring in English, as well as English major students, are able to experience English in a natural, interesting, and familiar way. It is to develop, analyze, and utilize contents that can maximize the effectiveness by increasing the concentration on the class. To achieve this objective, contents of the lecture consisted of the scenes, dialogues, and OSTs of the movie that the learners of different age with various academic backgrounds and life experiences could have interest in common. The theory of meaningful learning (Ausubel, 1963) is a frequent subject of English learning with communication - oriented teaching method. The meaningful learning is aimed at providing meaningful learning to learners considering the situation of learners, purpose of learning, and need. H. D. Brown (2001) also states that "meaningful learning will lead toward better long-term retention than rote learning (p. 57)." "Meaningful learning subsumes new information into existing structures and memory systems, and the resulting associative links create stronger retention" (H. D. Brown, 2001, p. 56-57). The materials and topics adopted in the curriculum should be closely related to the learner's real life and interests (Park \& Kang, 2014).

This is also connected to content-based second language instruction which has the advantage of not only acquiring language but also learning various knowledge and information, and also stimulating interest of learners (Brinton, Snow, \& Wesche, 1989). In order for learners to interact with the data more effectively, it is necessary to provide learning materials familiar to the learners, to enable them to respond to other learners through e-mail and list sub-services, or to provide diverse and rich teaching materials (Lim, Choi, Leem, \& Jung, 2000).

In order to effectively present these lessons, the content was strategically developed and 
produced using PowerPoint ${ }^{1}$ and Prezi (a new concept PowerPoint), ${ }^{2}$ based on Gagné's (1985) nine professions. In particular, the lecture that illuminates his life through the paintings of Van Gogh, was attempted to stimulate emotions by approaching in storytelling format using the Prezi tool (zoom-in, zoom-out, turn-over and rotation) and tried to make a lively presentation as if students could appreciate the pictures in the gallery. A series of lectures introduce a storytelling presentation technique using YouTube video, PowerPoint, and Prezi to create a customized content design that strategically approaches creative ideas. In addition, as mentioned in $\mathrm{Oh}$ (2003), most cyber university learners are not in a position to invest a lot of learning time, so that the class organization should be structured in a simple and structured way to facilitate learning management.

Therefore, in this paper, first, we will introduce the features of PowerPoint and Prezi used as presentation tools, and compare the strengths and weaknesses of the two techniques. Then, we will take a closer look at the online content production process using these techniques. Finally, through the questionnaire, the responses of learners to this contents will be investigated, and the most preferred learning model for learners will be presented.

\section{RESEARCH BACKGROUND}

In literature review, Lee (2003) points out the quality of the class, the quality of the contents, and the quality of the cyber education system as factors that directly affect the enrollment and re-enrollment rates of students. Jung, Lim, Choi, and Leem (1999) also suggests that in the web environment for realizing lifelong education, various factors such as text, graphics, voice, video and animation can be included to cope with various variables of learners. According to Lee and Lee (2006), although there are educational engineering macroscopic studies on cyber universities so far, a detailed research conducted in each subject area is insufficient. Yang, Wang, and Chie (2014) proposes the viewpoint of how

\footnotetext{
${ }^{1}$ Microsoft PowerPoint (or simply PowerPoint) is a presentation program, created by Robert Gaskins and Dennis Austin at a software company named Forethought, Inc. It was released on April 20, 1987, initially for Macintosh computers only. Microsoft acquired PowerPoint for $\$ 14$ million three months after it appeared. This was Microsoft's first significant acquisition, and Microsoft set up a new business unit for PowerPoint in Silicon Valley where Forethought had been located. Microsoft PowerPoint is one of many programs run by the company Microsoft and can be identified by its trademark orange, and P initial on the logo. It offers users many ways to display information from simple presentations to complex multimedia presentations. ("Microsoft PowerPoint", n.d., para. 1)

2 Prezi is a presentation software company founded in 2009, with offices in Budapest, San Francisco, and Riga According to the company, as of April 2018, Prezi had more than 100 million users who had created more than 325 million public presentations that have been viewed over 3.5 billion times. The word Prezi is the short form of "presentation" in Hungarian. ("Prezi", n.d., para. 1)
} 
technology fosters learning, a tripartite structure of effective technology-enhanced learning, through the development of technology, multimedia learning theories and current findings from empirical studies on technology-enhanced learning. This tripartite structure indicates that the design of technology-enhanced learning environment should concurrently consider learner characteristics, technology attributes and instructional methods. This facilitates learners in achieving upmost learning effectiveness. Hyerle (2009) suggests the use of visual tools to guide thinking when we need to simultaneously pay attention to the whole and analyze whether the parts are, indeed, interdependent and interconnected. Visual tools are one means of describing how a system functions when altered or when innovative thinking in one part of the system affects the total system. Hyerle commends interactivity as tools are developed in cooperative settings. Such tools assist in developing students' and teachers' capacity for flexibility-viewing situations from multiple perspectives, as well as being able to change and adapt based on feedback from others. Using such cooperative tools transcends the sense of self-enlarging the conception of "me" to a sense of "us."

\section{PowerPoint vs. Prezi}

First, the difference between the two techniques is that PowerPoint can be written and presented without the Internet, while the Prezi technique is basically a tool to create and publish on the Internet based on the cloud. The former is a slide-by-slide format, while the latter is a format that displays pictures and texts arranged on screen and sequentially presented by clicking. Prezi has the advantage of being able to lead the lecture more interestingly because it displays its contents in storytelling format.

The biggest feature of the Prezi is to have such functions as a zoom-in, zoom-out, turnover and rotation. Therefore, the instructor manipulates the text or the picture on the screen in the flow of the story, and draws the lecture more dynamically, which can lead to increase students' attention and interest. However, while Prezi is excellent in terms of this presentation function, PowerPoint also has an advantage in that learners can print out the lecture notes it has produced. In addition, PowerPoint is a universally used tool, so there is no compatibility problem, but there is the problem in the case of Prezi. Since Prezi is not yet a popular program, inexperienced users often find it difficult to edit and modify data. As a result, if the two techniques are properly used in parallel with producing lectures, the effect will be maximized. In this paper, a discussion of effectiveness of the two techniques will be made based on the survey results from the learners. 


\section{TABLE 1}

Presentation Software: PowerPoint vs. Prezi

\begin{tabular}{|c|c|c|}
\hline & PowerPoint & Prezi \\
\hline Logo & b $\frac{\overline{\bar{n}}}{\overline{3}}$ & 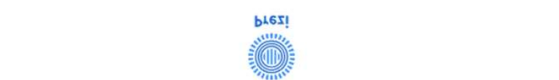 \\
\hline Pros & $\begin{array}{l}\text {-It is available without the Internet. } \\
\text {-Pre-designed layouts allow for } \\
\text { presentations to be assembled quickly. } \\
\text {-A wide range of transitions are } \\
\text { available from subtle to showy. } \\
\text {-The software is extremely easy to use } \\
\text { and most employees will have prior } \\
\text { experience of using it. } \\
\text {-PowerPoint slides can be printed out } \\
\text { and issued as handouts to facilitate } \\
\text { learning. } \\
\text {-It is a universally used tool, so no } \\
\text { compatibility problem. }\end{array}$ & $\begin{array}{l}\text {-The HTML5-based software can be used } \\
\text { in-browser, with no need to download } \\
\text { software. } \\
\text {-Prezi's zoom function allows the presenter } \\
\text { to jump to discussion points before } \\
\text { zooming out again- a feature that } \\
\text { Microsoft has since emulated in Zoom for } \\
\text { PowerPoint. } \\
\text {-Because Prezi starts with a blank canvas, } \\
\text { the onus is on the user to use their } \\
\text { initiative. As a result, presentations are } \\
\text { likely to be less formulaic than those } \\
\text { created by PowerPoint novices. } \\
\text {-Prezi is arguably more suited to inserting } \\
\text { audio and video into slides. }\end{array}$ \\
\hline Cons & $\begin{array}{l}\text {-It is a slide-by-slide format so that } \\
\text { there's a tendency for PowerPoint } \\
\text { presentations to look samey. } \\
\text {-PowerPoint can be used, usually by } \\
\text { purchasing Microsoft Office. }\end{array}$ & $\begin{array}{l}\text {-It is available only on the Internet based on } \\
\text { the cloud. } \\
\text {-Its slides also aren't optimised for } \\
\text { printing, unlike PowerPoint, and Prezi's } \\
\text { pre-designed templates aren't easily } \\
\text { customized. }\end{array}$ \\
\hline
\end{tabular}

\section{Purpose}

As a part of the emotional English project, this study was conceived in the point that it is necessary to develop a curriculum that evokes the power of reason and emotion, which are the domain of a human being, but which are increasingly dominated by machines and robots. The world is evolving rapidly. The power of reason, which has been regarded as a unique domain of a human being, has been threatened by artificial intelligence (AI), machines and robots. In this age, paradoxically, human warmth is more demanded. Therefore this study was conducted in order to develop and construct a curriculum to improve English proficiency, which became more important in leading the global era, at the same time, using audiovisual materials, to stimulate emotion for students to gain empathy.

To this end, the lesson gathered materials that can naturally lead learners to speak English through stories and contexts, focusing on topics that everyone can experience in everyday life. In order to stimulate visual and auditory senses, English expressions and vocabularies were selected focusing on the movie scenes and famous lines. The lecture 
was designed to learn English, listening to and singing along movie theme songs (OSTs). Students were encouraged to read English texts with the topic such as work, love, friendship, self-development, and death, and induced to broaden their thinking through reading. The lecture was carefully planned to cover literacy knowledge on social, cultural, artistic, and English native speakers' values.

The goal of this lecture is to encourage students to study English with attention and interest through the lines of main characters in the film and messages given in a movie. At the same time, listening to the movie OST, concentrating on the lyrics, students naturally become accustomed to English pronunciation, accent and liaison. Also, through film and music, students can develop serious thoughts and insights on topics such as life, love, farewell, death, sorrow, and war. Students gain confidence in English by making good use of English expressions learned in class.

The purpose of this study is to develop and construct lecture contents that other students who are not majoring in English, as well as English major students, are able to experience English in a natural, interesting, and familiar way. It is to develop, analyze, and utilize contents that can maximize the effectiveness by increasing the concentration on the class. Therefore, a lecture using Prezi technique, which is a new concept PowerPoint, in addition to existing PowerPoint, will be created, and the responses of learners will be investigated. It introduces a storytelling presentation technique using video, PowerPoint, and Prezi to create a customized content design that strategically approaches creative ideas. As a result, the goal is to present the most preferred learning model for learners.

\section{Scope and Method}

This study introduces the content of online English course offered at a cyber university in Seoul, and examines the impact and effectiveness of the lecture design used in the content. First, in the first part of this study, we will look at the information about the English class, which was produced as a core liberal arts course, the teaching-learning strategy, the learner and learning environment analysis, the content analysis, and the lecture in detail by list. A survey for the students participating in the class will be conducted to analyze the effectiveness and achievement of the learning effect of the content item. Based on the results of analyzing questionnaires, the most preferred learning model for students will be suggested.

J. D. Brown (2001) defines language survey as "that gather data on the characteristics and views of informants about the nature of language or language learning through the use of oral interviews or written questionnaires" (p. 2). In this paper, the questionnaire is defined as a 'written questionnaire' in a narrower sense. Because, often, the questionnaire is thought to be solely a written question, and the design and analysis of the interview are 
very different from the survey in general.

According to Dörnyei (2003), the survey can provide three types of information. The first is factual information, the second is behavioral information, and the third is attitudinal information. The survey for 'fact-based information' is used to learn more about the characteristics of teachers and students, such as students' gender, race, language background, and language proficiency. 'Information on behavior' is used to find out what a student or a teacher has been doing or learning regularly in learning and teaching language. For example, questions are such as "how often you look for a dictionary when you are looking at unfamiliar words," or "how often you think about the overall outline before writing an essay." On the other hand, the questionnaire asking 'information about attitude or thinking' is composed of questions that want to know about teacher, student's opinions, beliefs or concerns. Of these three types, in this study, students will be asked to answer questions by writing a questionnaire to find out about the third type of attitude or way of thinking. There are four questions, and the contents of the questions are attached as appendices. ${ }^{3}$ As Dörnyei (2003) notes that surveys are an effective way for researchers to gather much information in a short amount of time at very little cost.

This study is based on Gagné's (1985) nine events of instruction to emphasize selfdirected learning. Robert Gagné is a behaviorist and cognitive theorist who believed strongly in the idea of a cumulative model of learning (Gagné, 1985). This cumulative model is characterized by the idea that learning new concepts and skills is built upon those already learned. For Gagné, using real-world learning experiences and examples is necessary for learners to engage with learning material when teaching. His theories are strongly believed in this study as well. In the ideal teaching scenario, Gagné comments that instructional designers' lessons would be geared towards enhancing prerequisite knowledge; providing content organization and cues for information retrieval; assuring student participation; and using informative and corrective feedback. For Gagné, providing learning guidance throughout each of the nine events is the m'ost important step towards developing an effective teaching session. Table 2 shows the content development strategy based on Gagné's (1985) nine events, with reference to Gagné, Briggs, and Wager (1992).

TABLE 2

Content Development Strategy Based on Gagné's (1985) Nine Events of Instruction Events Content development strategy

1. Gain attention -Provide the subject, the professor's name, and the subject of the unit, so that students can prepare for learning. -By using typography in the title of a subject, expressing the personality

${ }^{3}$ For more information, please refer to IV. SURVEY RESULTS AND ANALYSIS. 


\begin{tabular}{|c|c|}
\hline & $\begin{array}{l}\text { and color of the subject, and inducing attention through the visual effect. } \\
\text {-Present the outline of the learning of the unit by a description of the } \\
\text { instructor and a text screen. }\end{array}$ \\
\hline $\begin{array}{l}\text { 2. Inform learners } \\
\text { of objectives }\end{array}$ & $\begin{array}{l}\text {-Present the main goal of learning using texts. } \\
\text {-Instructor explains and encourages expectation of learning. } \\
\text {-Present the title and detail of the main subject by using text. }\end{array}$ \\
\hline $\begin{array}{l}\text { 3. Stimulate recall } \\
\text { of prior Learning }\end{array}$ & $\begin{array}{l}\text {-Briefly introduce what is learned in the previous lecture. } \\
\text { - Before the start of learning, check the students' prior knowledge of the } \\
\text { contents in the unit through simple questions. }\end{array}$ \\
\hline $\begin{array}{l}\text { 4. Present the } \\
\text { content }\end{array}$ & $\begin{array}{l}\text {-Provide learners with a quick and easy way to understand their learning } \\
\text { contents: presentation slides using general images and texts. } \\
\text {-Provide instructor's video lecture, emphasizing important parts in writing. }\end{array}$ \\
\hline $\begin{array}{l}\text { 5. Provide } \\
\text { "learning } \\
\text { guidance" }\end{array}$ & $\begin{array}{l}\text {-The learning contents are modularized step by step and divided into three } \\
\text { classes based on the contents of learning. } \\
\text {-Induce the students to recognize the contents presented, using structured } \\
\text { directions and narration. }\end{array}$ \\
\hline $\begin{array}{l}\text { 6. Elicit } \\
\text { performance } \\
\text { (practice) }\end{array}$ & $\begin{array}{l}\text {-Present exercises related to learning contents and organize them so that } \\
\text { students can voluntarily perform them. } \\
\text {-A total of three exercises are presented to induce performance. }\end{array}$ \\
\hline $\begin{array}{l}\text { 7. Provide } \\
\text { feedback }\end{array}$ & $\begin{array}{l}\text {-Provide immediate feedback on performance results by providing } \\
\text { answers. } \\
\text {-Provide an explanation of the questions so that additional learning can } \\
\text { take place. }\end{array}$ \\
\hline $\begin{array}{l}\text { 8. Assess } \\
\text { performance }\end{array}$ & $\begin{array}{l}\text {-The learner compares the answers he/she thinks with the correct answers } \\
\text { presented by the instructor, which allows them to perform voluntary } \\
\text { evaluation. }\end{array}$ \\
\hline $\begin{array}{l}\text { 9. Enhance } \\
\text { retention and } \\
\text { transfer to the job }\end{array}$ & $\begin{array}{l}\text {-Present the main contents of the learning using text and provide time for } \\
\text { organizing the learning of the unit. } \\
\text {-Provide the topic and main contents of the next unit. }\end{array}$ \\
\hline
\end{tabular}

\section{OVERVIEW OF ONLINE CONTENTS}

\section{Course Outline}

This course has been prepared as an online lecture content as a core liberal arts curriculum of a cyber university which is located in Seoul. Therefore, students of various majors have applied for the course, in which the number of students are limited to 200. It is designed to help students understand the culture, lifestyle, and values of Englishspeaking countries. The students learn useful English expressions and idioms, focusing on major dialogues of films and lyrics of OSTs which are carefully selected for education. It is also designed to develop interdisciplinary curriculum and improve thinking and communication skills by combining English language skills and liberal arts education, which are essential in the era of globalization. Through the lessons, learners have some knowledge of various fields and widen their knowledge to be well equipped with integrated thinking abilities. They are exposed to movies and music in English-speaking 
countries, and develop their ability to analyze their ways of thinking, values, society, culture and history. At the same time, they learn useful vocabularies and expressions through movie scenes and lyrics of OSTs. The course was also focused on practice of listening to English by making full use of audiovisual materials. Learners, then, were instructed to sing along with theme songs and to practice their speaking spontaneously.

The lecture consists of a total of 14 weeks, which were produced using web design and eStream Presto techniques. Each unit is covered by video and voice lecture using Presto. The presentation method is not only using PowerPoint but also the Prezi tool, which provides lecture contents designed to deliver visual messages to learners efficiently. It is designed to improve the quality of instruction and stimulate interest in learning. It also provides learners with an opportunity to compare the strengths, weaknesses, or effectiveness of the two presentation tools. Students were introduced to the film every week to understand the theme, characters, and cultural and historical context of the film. They understand useful English expressions and the message that the movie conveys through. They become familiar with the meanings of the film's OST, interpretation of the lyrics, pronunciation, accent, and intonation.

\section{Contents Development}

\section{1) Teaching-Learning Strategy}

Teaching-learning strategies consist of teacher-centered explanatory class and discussion-based instruction. Through easy and clear explanations based on the instructor's knowledge and experience, learners are able to learn basic English expressions and contents effectively. At the same time, the learner is exposed to various ideas through online discussions with classmates to prevent uniformity of thinking, to build bonds between teacher and learner, and also learner and learner. The strategy is to raise a sense of solidarity.

\section{2) Learning Development Strategy}

The whole structure consists of 14 weeks, and has a repetitive learning structure with a 75-minute running time per week. Learning objectives and content summary are presented, and learning contents are classified by small subjects. The main topics of the weekly lectures are as follows: 
TABLE 3

Main Topics of the Weekly Lectures

\begin{tabular}{cc}
\hline \hline Unit & Topic \\
\hline 1 & Film: Notting Hill (Michell, 1999) \\
2 & OST: When You Say Nothing at All \\
3 & Film: Leon (Besson, 1994) \\
4 & OST: Shape of My Heart \\
5 & Film: Free Willy (Wincer, 1993) \\
6 & OST: Will You Be There \\
7 & Film: Days of Thunder (Scott, 1990) \\
8 & OST: The Last Note of Freedom \\
9 & Film: Titanic (Cameron, 1997) \\
10 & OST: My Heart Will Go on \\
11 & Film: Bridget Jone's Diary (Maguire, 2001) \\
12 & OST: Someone Like You \\
13 & Film: Loving Vincent (Kobiela \& Welchman, 2017) \\
14 & OST: Starry Starry Night \\
\hline
\end{tabular}

\section{3) Content Presentation Design Strategy}

Based on Gagné's (1985) nine theories of teaching profession, self-directed learning is emphasized by applying each stage design method and constructing contents. In addition, the design contents are presented intuitively and proceeded to the close relationships by object-oriented learning unit considering cognitive load of learning contents.

\section{FIGURE 1}

\begin{tabular}{|l|}
\hline \multicolumn{1}{|c|}{ Getting into } \\
\hline - Learning \\
Objectives / \\
Contents \\
- Review \\
- Prior learning \\
\hline VOD \\
\hline
\end{tabular}

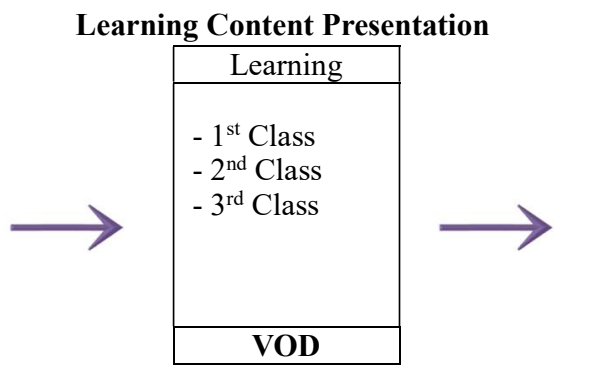

\begin{tabular}{|l|}
\hline \multicolumn{1}{|c|}{ Organizing } \\
\hline - Exercises \\
- Summary of the \\
main points \\
- Notice of next \\
unit \\
\hline \multicolumn{1}{|c|}{ VOD } \\
\hline
\end{tabular}

\section{4) Weekly Repetitive Teaching-Learning Structure Design Strategy}

Weekly repetitive teaching-learning structure design strategy induces attention to learning, providing information guidance and visual effects such as subject, professor and the topic of unit. Further, it is structured so that the composition of learning contents can 
be seen at a glance, so that students can freely choose their learning phase.

\section{5) Design Strategy for Motivation}

By attaching visual screen design and sound that take advantage of the characteristics of the subject for attention, teachers can direct the students to focus on learning. Further, students are forced to concentrate on learning by adding visual screen design and sound. In addition, the entire User Interface (UI) is placed to be recognized intuitively, and the learning is carried out with only the necessary functions. Texts, images, and writing on the board are provided to encourage learner attention, depending on the importance of learning. Learning goals of each unit are presented, using professor's explanation and text, to make them clear.

To increase the relevance, learners are made to feel familiar with lecture contents by using images related to subjects. By detailing the learning objectives and the sequence of the learning, students are able to recognize clearly what they need to accomplish from the unit in advance. It provides a comprehensive image or text for the learners to understand the learning contents easily and quickly. Students are able to expect the next lesson by checking what is learned in the following week.

In order to increase confidence, the guidance and goal of every unit are provided, so that presenting the direction of learning, the positive expectation effect of achieving the goal is provided.

Finally, it provides an opportunity to apply what we learned through the exercise to feel satisfaction. The learner's voluntary evaluation was made through instant feedback on the problem solving. It also provides the core contents of the learning so that students can check if the learning is well done. The evaluation questions were issued within the scope of learning at the end of each unit, and the learner was satisfied that the content of the learning was appropriately evaluated. The participants were encouraged to engage in active learning activities such as questioning and discussion through the bulletin board.

\section{6) Interaction Design Strategy}

For interaction between learners and contents, concrete contents using multimedia; movable navigation during learning; exercises and learning arrangements to identify learning content; feedback on exercises; and a lecture note on the main content of the lesson were provided.

For the interaction between the learner and the instructor, general lecture introductions and examinations / assignments using the notices were introduced. One-on-one counseling was provided through the [Question to Professor] menu, and feedback on quizzes and 
exams was provided. Students were encouraged to learn through the provision of learning materials and feedback on themes using discussion bulletin board.

For the interaction between learners and learners, students were encouraged to introduce themselves and greet one another using the bulletin board. The discussion bulletin board was used to exchange opinions on topics. They also shared information about free communication and learning, and were encouraged to share learning materials using subject bulletin boards.

For the interaction between the learner and the tutor, questions and suggestions about the lesson were answered. Individual consultations were conducted from time to time, using e-mail, a note, and [question to the operator] bulletin board. In order to facilitate learning, the tutor sent letters or consulted through the phone. Information about free communication and learning was shared using the bulletin board.

\section{7) UI Layout}

Interface design strategy Top-Left type was chosen as the base. Subject names, unit names and professor name were displayed in the title area, and subordinate concepts were hierarchically displayed in the main learning area with the learning control menu. In the text area, the learning content, controller, etc. are displayed as real learning contents. The secondary learning menu area includes University Identity, Copyright, Page Navigation, and so on.

\section{8) Strategies to Improve Content Accessibility and Learning Convenience}

The first is to provide sensible, clear, and various free navigation, and the design of the navigation system provided free movement between the content pages of the course. Second, the layout was designed to be easy to understand at a glance. It was placed in a position that is easy for learners to find, and the function name was clearly given. In other words, the strategies helped learners to think and learn immediately. Third, the learning contents page minimized the time required to access and provided the whole learning structure that can be checked by learners. It was also structured to clearly communicate the learning structure and scope. Fourth, we designed the page that minimizes screen scrolling so that important pages can be linked and branched instantly. Fifth, the icons used in the learning screen were designed in various designations, shapes and functions. Sixth, interaction design considering user-friendliness was studied. 


\section{9) Applying the Prezi Technology}

In the 13th week, all of the first, second, and third classes were produced by applying the Prezi technique. Prezi is a tool that can design the screen to focus attention to the end by using space and motion, not planar slides, to create more interesting, persuasive, and impressive presentations. In particular, the lecture that illuminates his life through the paintings of Van Gogh, was attempted to stimulate emotions by approaching in storytelling format using the Prezi tool and tried to make a lively presentation as if students could appreciate the pictures in the gallery. The responses to this technique were surveyed.

\section{SURVEY RESULTS AND ANALYSIS}

\section{Survey Questions and Results}

The survey was conducted in the form of a questionnaire, and 167 out of 200 enrolled students participated. The questions and the results included in the questionnaire are as follows:

1) Did the method of presenting the contents using the motion (zoom in) of the Prezi tool help you to grasp the structure of the learning contents (hierarchy)? [Selective questionnaire: Selection Number (1)]

TABLE 4

Selective Questionnaire: Selection Number (1)

\begin{tabular}{ccccc}
\hline \hline It really is & Yes & Normal & No & Not very \\
\hline $79 / 167$ students & $57 / 167$ & $30 / 167$ & $1 / 167$ & $0 / 167$ \\
$47.31 \%$ & $34.13 \%$ & $17.96 \%$ & $0.6 \%$ & $0 \%$ \\
\hline
\end{tabular}

As shown in Table 4, asked if the use of the motion (zoom in) of the Prezi tool was helpful, 79 of the 167 respondents answered "It really is," 57 responded "yes" and 30 responded "normal." Only one participant answered "no."

2) Depending on your learning topics, did the changes in the screen layout and design of the 1st, 2nd and 3rd class help you reduce the learning boredom and concentrate on learning? [Selective questionnaire: Selection Number (1)] 
TABLE 5

Selective Questionnaire: Selection Number (1)

\begin{tabular}{ccccc}
\hline \hline It really is & Yes & Normal & No & Not very \\
\hline $80 / 167$ students & $60 / 167$ & $25 / 167$ & $2 / 167$ & $0 / 167$ \\
$47.9 \%$ & $35.93 \%$ & $14.97 \%$ & $1.2 \%$ & $0 \%$ \\
\hline
\end{tabular}

To the question 2 , which the screen composition and design changes have helped to reduce the boredom of learning and to concentrate on learning, 80 of the 167 respondents answered "It really is," 60 responded "yes" and 25 responded "normal." 2 participants answered "no," as we can see in Table 5.

3) Did the content presentation method through message design (screen composition using visual materials) rather than a simple text listing help to understand the learning contents? [Selective questionnaire: Selection Number (1)]

TABLE 6

Selective Questionnaire: Selection Number (1)

\begin{tabular}{ccccc}
\hline \hline It really is & Yes & Normal & No & Not very \\
\hline $78 / 167$ students & $65 / 167$ & $24 / 167$ & $0 / 167$ & $0 / 167$ \\
$46.71 \%$ & $38.92 \%$ & $14.37 \%$ & $0 \%$ & $0 \%$ \\
\hline
\end{tabular}

To the question 3, which the content presentation method through message design (screen composition using visual materials) helps to understand the learning contents, 78 of the 167 respondents answered "It really is", 65 responded "yes" and 24 responded "normal. Nobody answered "no" "not very," in this question.

4) Please feel free to write any other comments about the lecture: "Strengthen the message design of visual materials using the Prezi tool." [A descriptive questionnaire]

A total of 91 students gave their opinions to Question 4. Of these, 73 gave positive feedbacks and 18 gave negative comments or suggestions. The responses of the students were categorized by the main keywords in Table 7 .

TABLE 7

Students' Responses to the Question 4 (A Descriptive Questionnaire)

\begin{tabular}{cc}
\hline \hline Keywords & Numbers of the responses \\
\hline Concentration & 32 \\
Interest & 20 \\
\hline
\end{tabular}




\begin{tabular}{ccc} 
& $\begin{array}{c}\text { A Case Study on the Contents Creation of Online Lectures } \\
\text { to Promote Interest and Concentration of Learners }\end{array}$ & 141 \\
\hline Visual effect & 15 \\
Comprehension & 14 \\
Freshness & 14 \\
Active participation & 7 \\
Use in other lessons & 3 \\
\hline
\end{tabular}

Some representative opinions of the keywords in Table 7 are summarized as follows. 32 people talked about the keyword Concentration. For example, "It was good because I could concentrate on learning without boredom. I was able to study interestingly because the materials came up new. It was a new way so that the materials came in at a glance." 20 students mentioned the keyword Interest. One of them is: "I know it's easy to say that Prezi is a moving presentation. I experienced it first in this class. First, I realized that the non-planar three-dimensional structure was fresh and vivid, so that it became a more exciting lesson. This lesson was more of a fun than a 'study,' so I was always interested in every unit. At the 13th, it was much more enjoyable to see the works of Van Gogh as if I were in the art gallery. In the future, I think that if the Prezi tool is used in other classroom, you can get more educational effect. Thank you professor." 15 people referred to the Visual effect: "New visual effects and composition did not cause boredom, and they were newly received every hour, which were more helpful for the concentration of the lesson." In case of Comprehension, 14 people mentioned the word: for example, "I was able to listen to the lecture more easily and it became easier to understand. I have always felt difficult to learn English, so it was very good to participate in the class with interest. The use of the Prezi tool helped to understand the lessons a lot." About Freshness, 14 people also gave positive opinions. One of them is "The immersion was the best. It was fresh. My eyes were less tired." 7 students mentioned about the word Active participation such as "The new learning model had made me actively involved in the class. The lesson invited my imagination. The first time I was introduced to the Prezi tool, it required more imagination than the general PowerPoint lecture." For Use in other lessons, 3 students strongly recommended that these various learning models should be applied to other classes.

TABLE 8

Suggestions and Comments

\begin{tabular}{cc}
\hline \hline Suggestions \& Comments & Numbers of the Responses \\
\hline Suggestions & 7 \\
Negative Comments & 5 \\
\hline
\end{tabular}

7 students made suggestions. Typical opinions are: "I think the Prezi technique introduced in the 13th week was good to understand the works of Van Gogh, but the normal PowerPoint method used in Unit 1 to 12 was also good because I could print out the lecture notes in the latter case;" "I thought that it would be a little difficult for the 
professor to stand for almost an hour and a half for the lecture. I think it would be nice to see her just sitting and lecturing comfortably;" "I prefer the lesson in which the professor points out each word to check and explain what it means because I can understand the meaning of the word correctly. For students who lack basic skills in English like me, the lesson with the Prezi tool was difficult to follow;" "I think if background music has also been added to the lecture, it would give more effect to make the lesson interesting."

There were also negative comments: for example, "In the PowerPoint lesson, the professor explained each word (or expression) one by one and it was easy to understand, but it's a little overpriced for a student who lacks fundamentals because the Prezi tool has to deliver it through a message; "I felt a bit dizzy in the lecture designed by the Prezi tool because the screen was changed before I could understand the contents on it;" "The new lecture model was not very helpful."

\section{CONCLUSION}

The purpose of this study was to introduce the development and production example of online English contents, to analyze learner responses to them, and to suggest more effective lecture contents and presentation techniques for learner's interest induction and concentration. First, for the contents of the lecture, movie scenes, the dialogue of characters, and its OSTs were selected to provide a common interest and attention with learners, based on the characteristics of the cyber university which have students of various ages, academic backgrounds and life experiences. In order to effectively present these learning materials, the lecture content was strategically developed and produced, based on the nine professions of Gagné (1985), along with the PowerPoint and Prezi techniques. 167 out of 200 enrolled students participated in the questionnaire, and more than $90 \%$ of the students gave positive opinions. Most of the students who participated in the questionnaire suggested that the way of presenting the contents, using the motions of the Prezi tool such as zoom-in, zoom-out, turn-over and rotation, was helpful. They answered that the change of screen composition and design according to the learning subject decreased the boredom of learning, and made them concentrate on class. There were 91 participants in the descriptive questions. Among them, 73 answered positively and 18 suggested improvement.

As a result, this study shows that the design model that is strategically created in terms of lecture contents and presentation composition is effective to attract attention and interest of learners. As Hyerle (2009) noted, featuring new research and examples, this practical resource focuses on brainstorming webs, graphic organizers, and concept maps to improve instruction and enhance students' cognitive development. In addition, this model can be 
used as an example of customized content designs that approach creative ideas strategically. It can contribute to the development of subjects that invite the power of reason and emotion, which is a human characteristic area, compared to the $4^{\text {th }}$ Industrial Revolution era led by machines and robots.

Since the late 1990s, the spread of the Internet has increased and the demand for elearning has increased throughout education as well as English education. Since then more and more diverse attempts have been made, e-learning education has developed rapidly. In Korea, cyber universities established in the early 2000 s have been struggling to make good quality online lecture contents for the last 18 years. Now, lectures have been popularized so that students can use mobile devices such as smartphones to listen to lessons. Therefore, it is necessary to make the lecture UI design more sophisticated and effective in order to increase the learning effect. In order to create learner-centered content that satisfies learners' psychology and desires, collaboration with UI/UX ${ }^{4}$ design experts is at a critical stage. Through this study, it was confirmed that the convergence of IT design with English education and the convergence of psychology and educational engineering are the alternative to lead the paradigm of education in the era of the $4^{\text {th }}$ Industrial Revolution. It is expected that a variety of instructional models will be designed and developed to maximize the expected effects of education.

This paper is a study on how the composition of the class using techniques such as PowerPoint and Prezi contributes to the interest of learners. This study is significant in that it shows an example of how technology-based learning can be utilized in the contents creation of online lectures to promote interest and concentration of learners. In future study, by conducting an experimental study comparing the group using Prezi and the control group not using it, the differences according to variables such as the students' pre-class experience, attitude, etc. will be examined. By looking at changes before and after classes, how Prezi affects English learning in addition to attracting learners' interest will be investigated. Inferential statistics will be used to verify the significance of the experimental study and to draw some convincing results.

\section{REFERENCES}

Ausubel, D. (1963). Cognitive structure and the facilitation of meaningful verbal learning. Journal of Teacher Education, 14, 217-221.

Besson, L. (Director). (1994). Léon [Motion picture]. France: Gaumont Buena Vista

${ }^{4} \mathrm{UI}$ is short for User Interface and UX is short for User eXperience. The UI is to consider how to approach it, and UX, based on user experience, is to make it easy for users to access. 
International.

Brinton, D., Snow, M. \& Wesche, M. (1989). Content-based second language instruction. Rowley, MA: Newbury House.

Brown, H. D. (2001). Teaching by principles: An interactive approach to language pedagogy (2nd ed.). White Plains, NY: Pearson Education.

Brown, J. D. (2001). Using surveys in language programs. Cambridge, UK: Cambridge University Press.

Cameron, J. (Director). (1997). Titanic [Motion picture]. United States: 20th Century Fox.

Dörnyei, Z. (2003). Questionnaires in second language research: Construction, administration, and processing. Mahwah, NJ: Lawrence Erlbaum.

Gagné, R. M. (1985). The conditions of learning and theory of instruction (4th ed.). Orlando, FL: Holt, Rinehart and Winston.

Gagné, R. M., Briggs, L. J., \& Wager, W. W. (1992). Principles of instructional design (4th ed.). Orlando: Harcourt Brace Jovanovich.

Hyerle, D. N. (2009). Visual tools for transforming information into knowledge (Vol. 2, $2^{\text {nd }}$ ed.). Thousand Oaks, CA: Corwin Press.

Jung, I., Lim, C., Choi, S., \& Leem, J. (1999). Development of teaching-learning model and virtual education program in web environment for realization of lifelong education. Social Education Research, 5(2), 85-111.

Kobiela, D., \& Welchman, H. (Directors). (2017). Loving Vincent [Motion picture]. Poland: Next Film.

Lee, J. (2003). 21segi julyeog seongjangmodel wongyeogdaehag baljeonbang-an yeongu [A study on the development plan of on-line university, 21C flagship growth model] (Education Policy Research 2003-appointed-31, 1-139). KERIS: Korea Education and Research Information Service.

Lee, Y., \& Lee, C. (2006). A study on the preference and attitude of learners on cyber university's online English teaching and learning contents. Multimedia-Assisted Language Learning, 9(3), 151-185.

Lim, C., Choi, S., Leem, J., \& Jung, I. (2000). The effect of interaction types on webbased learning for lifelong education. Journal of Educational Technology, 16(1), 223-246.

Maguire, S. (Director). (2001). Bridget Jone's diary [Motion picture]. United States: Universal Pictures.

Michell, R. (Director). (1999). Notting Hill [Motion picture]. United States: Universal Pictures.

Microsoft PowerPoint. (n.d.). In Wikipedia. Retrieved November 11, 2018, from https://en.wikipedia.org/wiki/Microsoft_PowerPoint.

Oh, Y. (2003). Analysis of difference in learning achievement according to learning style 
and self-regulated learning in web-based learning. Unpublished. MA thesis. Sookmyung Women's University.

Park, E. \& Kang, H. (2014). A case study of on-line contents design and students' participation in English conversation course. Humanities Research, 48, 407-438. Chosun University Institute of Humanities.

Prezi. (n.d.). In Wikipedia. Retrieved November 8, 2018, from https://en.wikipedia. org/wiki/Prezi

Scott, T. (Director). (1990). Days of thunder [Motion picture]. United States: Paramount Pictures.

Wincer, S. (Director). (1993). Free Willy [Motion picture]. United States: Warner Bros.

Yang, K., Wang, T., \& Chie, M. (2014). How technology fosters learning: Inspiration from the "media debate." Creative Education, 5(12), 1086-1090.

APPENDIX

Learner Questionnaire

\begin{tabular}{|c|c|}
\hline $\begin{array}{c}\text { Course } \\
\text { Information }\end{array}$ & General English \\
\hline Question time & June 4 (Monday), 2018 - June 13 (Wednesday), 2018 \\
\hline \multicolumn{2}{|c|}{ [Strengthen message design of visual materials using the Prezi tool] } \\
\hline \multicolumn{2}{|r|}{ Content Survey } \\
\hline \multicolumn{2}{|c|}{ Hi. This is OO Cyber University Teaching and Learning Support Team. } \\
\hline \multicolumn{2}{|c|}{$\begin{array}{l}\text { To improve the quality of teaching and to stimulate learning interest, this subject provided } \\
\text { lecture contents through the design of the message (learning contents) of the visual data } \\
\text { using the Prezi tool (13th week) on a pilot basis. In this regard, we would like to ask you } \\
\text { briefly about whether it will help students and improve their learning. Your valuable } \\
\text { answers will be reflected in the future, and it will greatly contribute to the expansion of the } \\
\text { scope of application of contents and the improvement of the quality level. Thank you. }\end{array}$} \\
\hline \multicolumn{2}{|c|}{ * Design using the Prezi tool } \\
\hline \multicolumn{2}{|c|}{ Screen design that focuses attention to the end by using space and motion, not a planar slide } \\
\hline \multicolumn{2}{|c|}{ By using motion (zoom in), the learning structure (hierarchy) can be grasped at a glance } \\
\hline
\end{tabular}


by showing the contents in detail in order of detail.

* Message (learning contents) design

How to present contents so that students can easily understand learning contents by using images, videos, charts, etc. instead of simple texts. $\rightarrow$ e.g. $1^{\text {st }}$ Class landscapes: Present related image by year

(Please mark the corresponding part with $\bullet$.)

\begin{tabular}{lcccccc}
\hline Questions & Really & Nes & Average & No & Not \\
& It is & & & & very \\
\hline
\end{tabular}

1. Did the method of presenting the contents using the motion (zoom-in) of the Prezi tool help you to grasp the structure ○ of the learning contents (hierarchy)?

2. Depending on your learning topics, did the changes in the screen layout and design of the 1st, 2nd and 3rd class help you reduce the learning boredom and concentrate on learning?

3. Was the content presentation method through message design (screen composition using visual materials) rather than a simple text listing help to understand the learning contents?

4. Please feel free to write any other comments about the lecture: "Strengthen the message design of visual materials using the Prezi tool."

A descriptive

Questionnaire

(Write your opinion) 
A Case Study on the Contents Creation of Online Lectures

Applicable level: higher education

Keywords: on-line contents, PowerPoint, Prezi, motion (zoom-in), questionnaire, survey

\section{Kang, Hye-Kyung}

Department of English

Open Cyber University of Korea

C-9F, Mangu-ro 353, Jungnang,

Seoul, 02087, Korea

Email: hkkang@ocu.ac.kr

Received: October 15, 2018

Revised version: November 14, 2018

Accepted: November 25, 2018 